\title{
Creativity in Family Medicine
}

\author{
Jose Luis Turabian* \\ Specialist in Family and Community Medicine, Spain \\ *Corresponding author: Jose Luis Turabian, Health Centre Santa Maria de Benquerencia, Spain

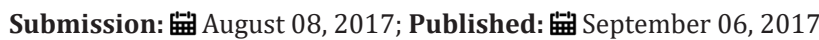

\begin{abstract}
The concept of creativity is important in medicine, especially in family medicine, to stimulate new ideas about research and patients care. Family medicine is the art of working with creativity. This concept can be difficult to explain and understand. This characteristic is presented based on a fable or tale "the fable of the golf ball and the penguin". The fable is an adult education method which can serve to intuitively understand abstract concepts, by linking them to specific situations, and so to facilitate their assimilation. The family doctor has to have great creativity to can be able to face the variability and complexity of people, contexts, patterns, models, actors and relationships. Creativity is one of the strategies used by the competent family doctor to resolve the uncertainty of decision making in the consultation. And within the options to can generate the growth of our creativity, one of them is when solution is adapted to different situation: how to use something effective elsewhere? What can we copy or imitate? How do they solve it in other cultures or other disciplines? How can we turn the problem into an opportunity? How can we put together used things and constitute something new?

Keywords: Family medicine; Fable; Significant learning; Methodological proposal; Creativity
\end{abstract}

\section{Introduction}

Conceptual systematization in the specialty of Family Medicine/ General Medicine has not matched with practice. However, it is not until that the conceptual heritage of Family Medicine, is ordered, systematized and fully clarified when it can begin the real practical work [1-5].

Therefore, it is necessary to achieve more meaningful representations of the fundamental concepts of Family Medicine, and facilitate the transfer of these to clinical practice. One of these main concepts is that of "creativity" [6]. But, this concept can be difficult to understand and explain, even for experienced physicians in the specialty [7,8]. Evidence-Based Medicine, clinical trials and quantitative studies are necessary, indispensable for medical science, but why not the stories, the tales and the cases? So, we will present this concept of "creativity" by a fable [9]. Fables and metaphors can simplify expert knowledge, not by ignoring or reducing the inherent complexity, but by providing a point of entry for its comprehension. They are a means of generating ideas, promoting creativity, and constructing concepts and theories $[10,11]$.

The fable is an adult education method that can serve to intuitively understand abstract concepts by linking them to specific situations, for facilitating their assimilation. The fable is a fictional stories presented as real. In the fable will be beings or objects that are given the opportunity to think, feel and speak. In the fable it can be distinguished two parts: one is the story itself the "case" or "clinical observation", and the other the moral $[12,13]$.

\section{Short Communication}

Once upon a time there was a golf ball that walking with instability and a penguin that seemed to move unsteadily but walked with great stability and they met at the family doctor's office. Mr. Golf Ball was an old ball consisting of a core of rubber-to give it elasticity and an outer layer of plastic. The surface had small, regularly distributed dimples to provide stability during flight. Mr. Golf Ball had spondyloarthrosis with cervical myelopathy, with dizziness or instability, as well as gait difficulty, and had had several falls, and I was afraid of new episodes.

Because of the restriction of activity that the patient or family established, due to lack of confidence and the anguish that a new fall produced in Mr. Golf Ball, aggressiveness and behavioural disorders had been triggered, with loss of self-esteem and an increase in social isolation with restriction of the activities of daily life. Mr. Golf Ball lived alone with his wife; although on the same building was his daughter. When the family members faced a fall often reacted with anxiety and they becoming over-protective, limiting the relative autonomy of Mr. Golf Ball. But, in addition, Mr. Golf Ball had formed an unpleasant character with aggressiveness towards his wife and demands for continuous care. A long treatment with antidepressants was ineffective, as well as the use of sedative drugs vestibular, and the neurologist discharged to him because of that "nothing could be done."

"I know that golf is a sport that consists of playing with a ball until it is thrown into a hole by successive blows. But I have fear 
falling into the hole. It is $108 \mathrm{~mm}$ in diameter and at least $100 \mathrm{~mm}$ of depth...! Another fall at my age would be terrible", said Mr. Golf Ball. And he added:

A. "And when I have to spin! Oh Lord!. And be on the green next to the hole! What dizziness!"

B. The doctor did not know how to intervene in this case. In other words; there was no way to solve it:

C. "The situation of the old Mr. Golf Ball, with his instability, I do not know how could be solved!"

The next patient was Mr. Penguin, who arrived with his typical and elegant appearance, for he was always dressed in a black and white suit.

A. "I'm getting better from my instability, Doctor. I have learned to move with this excessive wobble from one side to the other, but I do not fall, and I can move with stability. Although penguins may seem to you, Doctor, unsuitable for rough terrain, we travel more than 120 miles per hour on rough terrain to reach our nesting sites. The penguins have learned to use the wiggling in a way that makes our movements more effective and adjusted in the limitations caused by our legs and weight."

B. "I understand! Penguins have great stability for walking, and understanding their strategy could have applications for the elderly. I have to be creative and imagine solutions outside of conventional protocols. And so by learning about the distinctive waddling of the penguins, it could help people with mobility problems, such as the elderly, or people with leg or foot injuries, like Mr. Golf Ball”, the doctor suddenly thought.

C. "The family physician has to make use of his creativity, original thinking and intuition, to capture peculiar details in the different planes of the search that are specific to each patient, and to integrate and relate dynamically with his experience And knowledge to arrive at preliminary or hypothetical new conclusions. I could use options such as: renew-simplify, condense, reorganize reanalyze elements differently, reorder, reschedule, and change, that to say, improve quality, eliminate defects, divide or fragment things".

D. "I mean, that I have to see the problems and their resolution as an adventure, a possibility of development, of inventing, of realizing, and of having fun. So, when you get surprised at the options you will have the best solutions", concluded the doctor.

\section{Summary and Conclusion}

There are many paths to climb in the attainment of knowledge. It seems, however, that over the last century the dominant approach in Western thought has only recognized the Cartesian positivist paradigm as a valid the process for gaining knowledge. Different types of problems require different types of knowledge. Creativity can be a source of knowledge by providing us with perspectives of reality, and in this sense it can also have a cognitive impact on us and on our understanding of the world. The prevailing belief in a measurable and deterministic truth has begun to disappear. We now accept that there are many forms of knowledge. Life, in its constant expansion and creativity, including uncertainty, provides us with open-ended, unwritten experiences, with changes and surprises. Thus, uncertainty is an essential element in human existence.

Family medicine is the art of working creatively. Creativity is one of the strategies used by the competent family doctor to resolve the uncertainty of decision making in the consultation. And within the options to generate our creativity, one of them is to adapt the solution to different situations: how to use something that was effective elsewhere? What can we copy or imitate? how do they solve it in other cultures or other disciplines? How can we turn the problem into an opportunity? How can we put together used things and constitute something new...? [14-20].

The family doctor has to be creative. He or she has to be as a jazz musician. The music that the "family doctor plays" in each consultation has to have great creativity to can be able to face the variability and complexity of people, contexts, patterns, models, actors and relationships [21-23].

Creativity is an emerging concept in a fast changing world, where it is no longer enough to learn the elaborated knowledge or apply the clinical guidelines when attending patients, but that in the context of medical care in family medicine it is necessary to give new answers to changing and serious problems. Thus, the family doctor should be trained as a creative professional [24].

\section{References}

1. Davies P (200) Is it time for a new definition of general practice? General practitioners' main interest is people. BMJ 321(7254): 173.

2. Povar GJ (1996) Primary care: questions raised by a definition. J Fam Pract 42(2): 124-128.

3. Turabian JL (1995) Cuadernos de Medicina de Familia y Comunitaria. Una introducción a los principios de Medicina de Familia.

4. Epstein RM, Hundert EM (2002) Defining and assessing professional competence. JAMA 287(2): 226-235.

5. Leach DC (2002) Competence Is a Habit. JAMA 287(2): 243-244.

6. Hesse M (1996) Models and analogies in science. Notre Dame: University of Notre Dame Press, USA.

7. Thomas P (2006) General medical practitioners need to be aware of the theories on which our work depend. Ann Fam Med 4(5): 450-454.

8. Olesen F (2003) A framework for clinical general practice and for research and teaching in the discipline. Family Practice 20(3): 318-323.

9. Sacks $O$ (1998) The man who mistook his wife for a hat. New York: Touchstone, USA.

10.Turabian JL, Perez-Franco B (2016) The Family Doctors: Images and Metaphors of the Family Doctor to Learn Family Medicine. Nova Publishers, Spain.

11.Turabian JL, Franco BP (2017) Responses to Clinical Questions: Specialist-Based Medicine vs. Reasonable Clinic in Family Medicine. Integr J Glob Health 1: p. 1.

12.Turabian JL (2017) Fables of Family Fedicine A collection of fables that teach the Principles of Family Medicine. Editorial Académica Española, Filipina.

13.Turabian JL (2017) Stories Notebook about the Fundamental Concepts in Family Medicine: An Introduction. J Gen Pract (Los Angel) 5: p. 1.

14. Rosa W (2016) Creativity The Work of Healing. J Holist Nurs 34(2): 109 $-111$. 
15.Villanueva Betancourt M, Atencio Sariol G (2001) Estimulación del pensamiento creativo en la enseñanza de las ciencias médicas (I). Rev Cubana Educ Med Super 15(2): 109-116.

16. Stephenson MJ, Bass MJ (1983) Creativity in management in family medicine. J Fam Pract 16(2): 347-350.

17. Fleet R (2014) On creativity and innovation Getting into the minds of creative giants at Family Medicine Forum. Canadian Family Physician 60(10): 950.

18. Ness, Roberta B (2011) Commentary: Teaching Creativity and Innovative Thinking in Medicine and the Health Sciences. Acad Med 86(10): 1201 1203.

19. Csikszentmihalyi M (1998) Motivation and creativity: Toward a synthesis of structural and energistic approaches to cognition. New Ideas in Psychology 6(2): 159-176.
20.Schubert DSP (1973) Intelligence as Necessary but Not Sufficient for Creativity. Journal of genetic Psychology 122(1): 45-47.

21. Haidet P (2007) Jazz and the 'Art' of Medicine: Improvisation in the Medical Encounter. Ann Fam Med 5(2): 164-169.

22. Miller WL (2001) Practice Jazz: Understanding Variation in Family Practices Using Complexity Science. J Fam Pract 50(10): 872-878.

23. Reid S (2008) Music as a metaphor for the medical consultation. South African Family Practice 50(1): 62-64.

24. Turabian JL, Perez Franco B (2009) Can fish live out of water? Implications for teaching the biopsychosocial concept in family medicine. Aten Primaria 41(11): 629-632. 